\title{
GARBAGE MONITORING SYSTEM USING GSM
}

\section{Pandiaraj Kadarkarai}

Assistant professor, Department of Electronics and Communication Engineering. Kalasalingam Academy of Research and Education, Krishnan koil, Tamilnadu, (India).

E-mail: pandiaraj@klu.ac.in

ORCID: https://orcid.org/0000-0001-9610-2172

\section{Sivakumar Pothiraj}

Professor, Department of Electronics and Communication Engineering. Kalasalingam Academy of Research and Education, Krishnan koil, Tamilnadu, (India).

E-mail: siva@klu.ac.in

ORCID: https://orcid.org/0000-0003-1328-8093

\section{Nandhini Venkatesakumaran}

Department of Electronics and Communication Engineering. Kalasalingam Academy of Research and Education, Krishnan koil, Tamilnadu, (India). E-mail: nandhinikumaran09@gmail.com ORCID: https://orcid.org/0000-0001-6509-8334

Parkavi Seenivasan

Department of Electronics and Communication Engineering. Kalasalingam Academy of Research and Education, Krishnan koil, Tamilnadu, (India).

E-mail: parkavi030599@gmail.com ORCID: https://orcid.org/0000-0002-2054-166X

\section{Gitación sugerida:}

Kadarkarai, P., Pothiraj, S., Venkatesakumaran, N., y Seenivasan, P. (2021). Garbage monitoring system using GSM. 3C Tecnología. Glosas de innovación aplicadas a la pyme, Edición Especial, (noviembre, 2021), 21-31. https://doi.org/10.17993/3ctecno.2021.specialissue8.21-31 


\section{ABSTRACT}

All over the world waste management is a major problem. Many times, we see that the dustbin placed at public places are overloaded. It creates unhygienic environment for the people. To avoid such things, we have implemented a project known as "Garbage monitoring system using GSM". These dustbins are supplied with low price embedded device that helps in tracking the amount of garbage in the bin. A unique ID is provided for each garbage can which helps to identify the location and the status of the bin. These details will be sent to the concern authorities, with the help of message an immediate action can be made to clean the garbage in the dustbin. Garbage monitoring system is a new idea of implementation which makes a normal dustbin smart using ultrasonic sensors for garbage level detection, display and sending message to the concern department person updating the status of the bin using GSM modem.

\section{KEYWORDS}

Arduino board, Ultrasonic sensor, GSM. 


\section{INTRODUCTION}

In order to preserve the surroundings from all the rubbish that is spread over the world which causes some harmful diseases in the surroundings, due to the accumulation of the municipal solid waste it leads to environmental pollution. A proper maintenance of waste is necessary for economical and effective removal of municipal solid waste. We tend to introduce this idea of Garbage monitoring system using GSM. People are depositing their waste within the garbage can. We are fitting ultrasonic sensor, at the highest of garbage can. Currently the ultrasonic sensor can sense the rubbish level (Jain \& Bagherwal, 2017). If garbage amount increases, shortly it'll reach the edge level. As shortly as the threshold value is attained, automatically alert will be sent using GSM module to the registered range, intimating that the rubbish value has reach the extent of about $5 \mathrm{~cm}$ nearby ultrasonic sensor.

The garbage cans are filled, and the data is sent to the concerned authority for the further process. We used the GSM for the real time information. It is the main part of the communication system which has less price, good performance and which can be implemented easily. If any of the person is making an attempt to deposit their waste within the garbage can, even though the threshold value crosses the range then the LED will glow. This method helps to reduce amount of time used, fuel, and money. There will be lots of rural places which can be benefitted from this technique in future.

\section{MATERIALS AND METHODS}

\subsection{EXISTING METHOD}

Garbage has to be collected manually and periodically whether the dustbin is full or Not.

Drawbacks of the present method

- Less effective

- More time consumption

- Expenditure will be high

- Filthy atmosphere 
- It creates bad odor and causes health problems.

\subsection{PROPOSED METHOD}

The embedded system is widely used in many areas, but the work done by this system will differ from place to place. The project explained here shows one of the uses of microcontroller with GSM and ultrasonic sensor. There is no proper indication of garbage level so the collections of waste in many areas are delayed which causes rotten smell and spread many diseases.

In this paper the "garbage monitoring system using GSM" is introduced. Here the garbage can place in remote areas are monitored through the sensor placed in the bin. To check the status of the dustbin, ultrasonic sensor is used. As, it reaches the threshold level the indication will be sent through GSM which is received by the android mobile which contains the location of the dustbin.

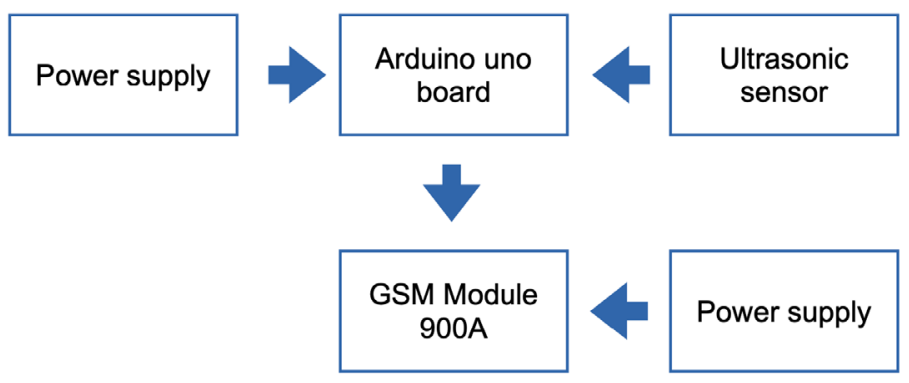

Figure 1. Garbage monitoring system using GSM (Block Diagram).

Source: own elaboration.

\section{WORKING}

The device consists of ultrasonic sensor, the Arduino Uno microcontroller, and the GSM module. Here we are going to discuss about the block diagram of the garbage monitoring system.

\section{A. HG-SR04 ULTRASONIC SENSOR}

To determine the distance of an object, the ultrasonic sensor (HC-SR04) is used. It offers excellent non-contact range from $2 \mathrm{~cm}$ to $400 \mathrm{~cm}$ or 1 " to 13 feet and it detects with high accuracy and stable readings, the status of the waste in the bin is detected with the help of 
this sensor and continues checking of garbage level takes place (Kumar et al., 2017). The readings will be sent to Arduino which acts as system controller.

\section{B. ARDUINO UNO}

The Arduino UNO is supported with microchip ATmega328P microcontroller and it is an open-source microcontroller board (Mirchandani et al., 2017; Dugdhe et al., 2016). The board is provided with sets of digital and analog input/output pins that may be interfaced with several alternative circuits and expansion boards.

The board has fourteen Digital pins, six Analog pins, and programmable with the Integrated Development environment which helps to program the device according to the need. In this project the Arduino board acts as the connector between the sensor and the GSM. The data which is provided by ultrasonic sensor is processed in the Arduino board and the command is sent to GSM.

The red LED which is connected to the Arduino board, as the garbage reaches certain level the LED will glow.

\section{GSM}

GSM (Global System for Mobile Communication) is a digital cellular technology used for transmission of mobile voice and data services which operates at the $850 \mathrm{MHz}, 900 \mathrm{MHz}$, $1800 \mathrm{MHz}$ and $1900 \mathrm{MHz}$ frequency bands. In this project GSM is used to send the message to the particular number after getting command from the Arduino board (Reddy et al., 2017; Thakker \& Narayanamoorthi, 2015). The message is sent as an indication to the authorized number with the address and status of the bin. 


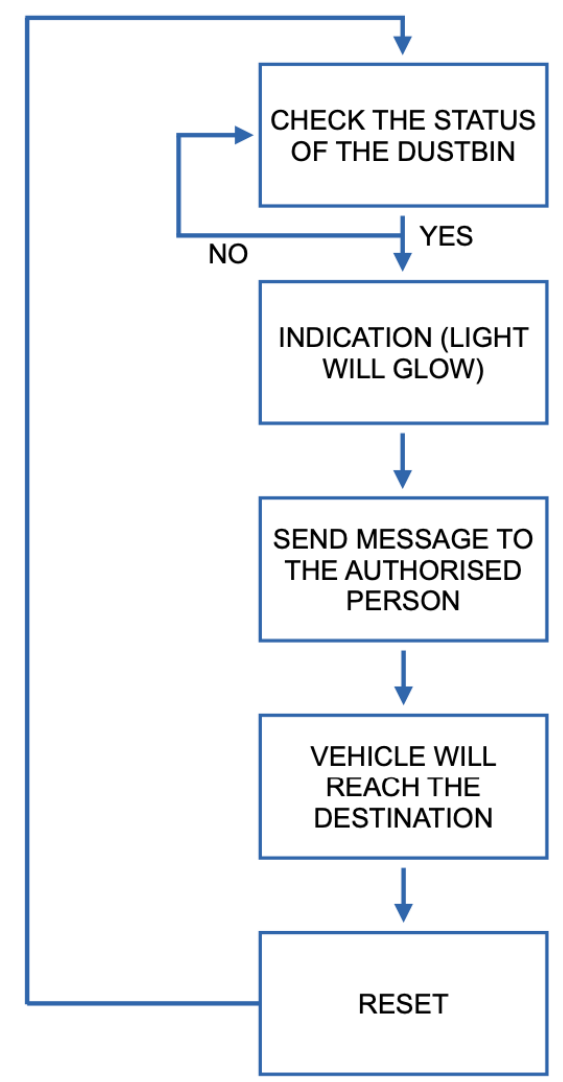

Figure 2. Flow chart.

Source: own elaboration.

As the flow chart represent the flow of working of the project, the status of the dustbin is checked continuously if the condition becomes true then the process goes to next level otherwise it continues with its checking process. When the condition is true the indication process starts, the LED which is present in the device glow and the message is sent to the authorized person with the provided information the vehicle will reach the destination. After the collection of the garbage the device will get reset.

\section{RESULTS}

In many areas, we can observe the dustbin has been filled. It is very unhygienic, and it will create many diseases to the people in and around the world so, we have introduced a new automated device called "GARBAGE MONITORING SYSTEM USING GSM". This device helps to clean the dustbin in time. To sense the level of the dustbin ultrasonic sensor 
is used (ie) (distance $<5 \mathrm{~cm}$ ) and the signal will be sent to the Arduino. Thereby, the signal will be sent to the GSM and the signal from GSM will be sent to the authorized person. In addition to the message, the LED will be glow until the dustbin is cleaned. This device can reduce the time consumption and transportation charge. After this device is implemented, the human interaction will be reduced.

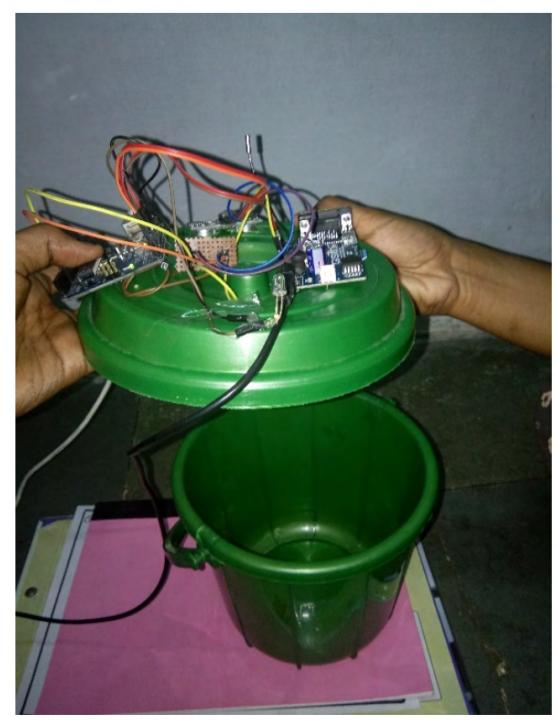

Figure 3. Dustbin is not filled.

Source: own elaboration.

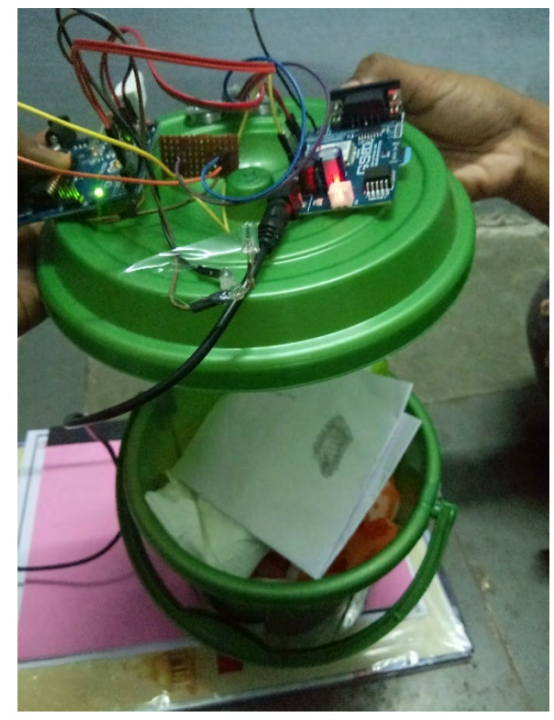

Figure 4. The Dustbin is about to fill.

Source: own elaboration. 


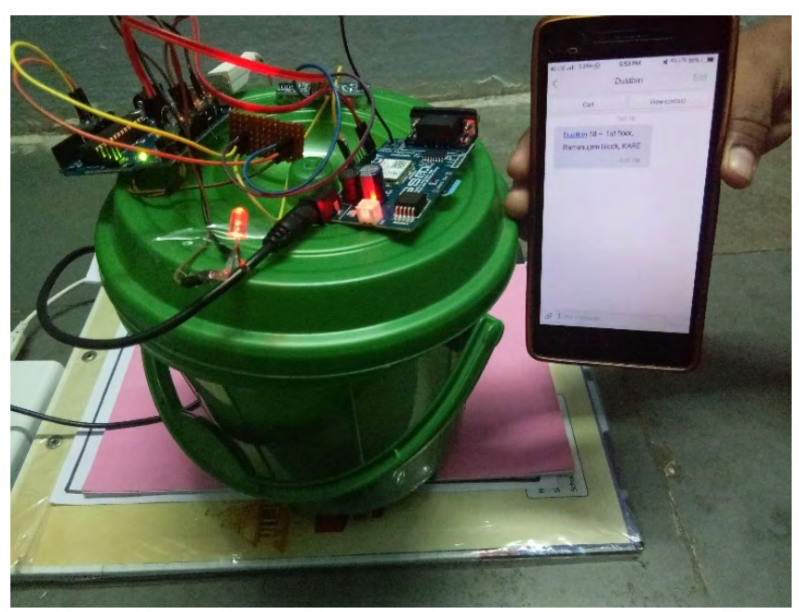

Figure 5. Output (Message received).

Source: own elaboration.

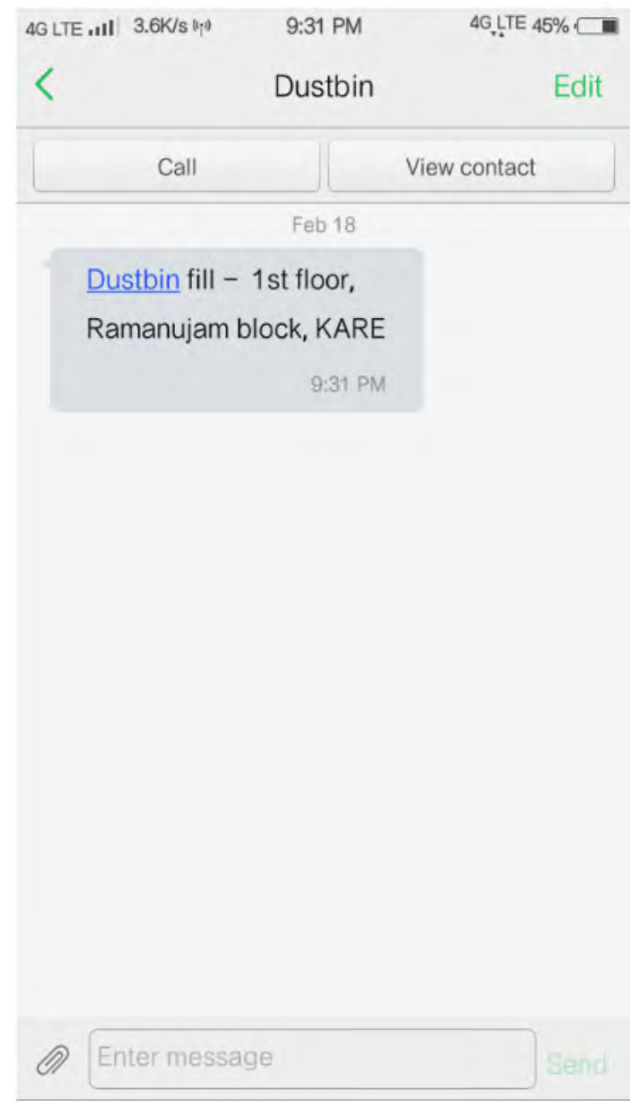

Figure 6. Message received.

Source: own elaboration. 


\section{CONCLUSIONS}

For correct maintenance and correct observation of the waste, an Arduino based wise alert system is devised. This method averts their regular cleanup of the garbage can by sending caution messages to the particular number periodically and it helps in the cleaning process in real time so this process can be considered as an outstanding performance for the surroundings. In this process it diminishes the number of human resources needed. Thus, the process of cleaning becomes faster compare to the manual process.

\section{REFERENCES}

Dugdhe, S., Shelar, P., Jire, S., \& Apte, A. (2016). Efficient waste collection system. In International Conference on Internet of Things and Applications (IOTA), pp. 143-147. https:// doi.org/10.1109/IOTA.2016.7562711

Jain, A., \& Bagherwal, R. (2017). Design and Implementation of a Smart Solid Waste Monitoring and Collection System Based on Internet of Things. In 8th International Conference on Computing, Communication and Networking Technologies (ICCCNT), pp. 1-5. https://doi.org/10.1109/ICGCNT.2017.8204165

Joshi, J., Reddy, J., Reddy, P., Agarwal, A., Agarwal, R., Bagga, A., \& Bhargava, A. (2016). Cloud computing based smart garbage monitoring system. In $3 r d$ International Conference on Electronic Design (ICED), pp. 70-75. https://doi.org/10.1109/ ICED.2016.7804609

Kumar, B. R. S., Varalakshmi, N., Lokeshwari, S. S., Rohit, K., Manjunath \& Sahana, D. N. (2017). Eco-friendly IOT based waste segregation and management. In International Conference on Electrical, Electronics, Communication, Computer, and Optimization Techniques (ICEECCOT), pp. 297-299. https://doi.org/10.1109/ ICEECGOT.2017.8284686

Kumar, N. S., Vuayalakshmi, B., Prarthana, R. J., \& Shankar, A. (2016). IOT based smart garbage alert system using Arduino UNO. In IEEE Region 10 Conference (TENCON), pp. 1028-1034. https://doi.org/10.1109/TENCON.2016.7848162 
Kumar, S. V., Kumaran, T. S., Kumar, A. K., \& Mathapati, M. (2017). Smart garbage monitoring and clearance system using internet of things. In IEEE International Conference on Smart Technologies and Management for Computing, Communication, Controls, Energy and Materials (ICSTM), pp. 184-189. https://doi.org/10.1109/ ICSTM.2017.8089148

Longhi, S., Marzioni, D., Alidori, E., Di Buo, G., Prist, M., Grisostomi, M., \& Pirro, M. (2012). Solid Waste Management Architecture Using Wireless Sensor Network Technology. In 5th International Conference on New Technologies, Mobility and Security (NTMS), pp. 1-5. https://doi.org/10.1109/NTMS.2012.6208764

Mirchandani, S., Wadhwa, S., Wadhwa, P., \& Joseph, R. (2017). IoT enabled dustbins. In International Conference on Big Data, Io T and Data Science (BID), pp. 73-76. https:// doi. org/10.1109/BID.2017.8336576

Reddy, P. S. N., Naik, R. N., Kumar, A. A., \& Kishor, S. N. (2017). Wireless dust bin monitoring and alert system using Arduino. In Second International Conference on Electrical, Computer and Communication Technologies (ICECCT), pp. 1-5. https://doi. org/10.1109/ICECGT.2017.8117960

Thakker, S., \& Narayanamoorthi, R. (2015). Smart and wireless waste management. In International Conference on Innovations in Information, Embedded and Communication Systems (ICIIECS), pp. 1-4. https://doi.org/10.1109/ICIIECS.2015.7193141 
